had not Thomas Wakley (1823-1862), his sons, James (1862-1886) and Thomas H. Wakley (1886-1905), and his grandson, Thomas Wakley, Jun. (1886-1908), and the present editorial staff initiated and carried on a campaign, first of all against the leaders of the medical profession itself and, afterwards, against all that was inimical to the medical profession and to the public interests. But, as the lay contemporary already referred to remarks, "on its hundredth birthday the Lancet has the reputation of being a serious and solemn medical newspaper. There is no sign at all in its careful pages of that romantic, violent, but withal, splendid past which was so very well known to our grandfathers." Times have changed and we with them. The fierce battle has been fought for the right, and the energy formerly directed towards reformation has been largely redirected towards information. Following upon the exposure of nepotism and malpractice, laziness and greed amongst the leaders of the profession, came the organized movement against tuberculosis, the treatment of insanity, the exposure of food adulteration by means of the Lancet Sanitary Commission, the enquiry into Workhouse administration, anaesthetics, Listerism, the foundation of Epsom College, the Medical Act of 1886, the registration of midwives and so on up to the present time; in all of which movements and discoveries the Lancet has taken a hand and often played a trump card. What with the domestic history of the Journal, the history of its activities, the sketches of character of past medical masters and the reproduction of their features (there are some fifty of these portraits including a colour reproduction of a Landseer sketch of Thomas 'Nakley) one cannot find a dull moment in the perusal of this, surely the most important piece of medical journalism ever attempted.

\title{
Monograph Supplements
}

Papers which are too long for insertion in one or even two numbers of this journal are occasionally submitted to the Editorial Committee. The subdivision of such papers is always unsatisfactory and often leads to less than proper justice being accorded to them. In some cases it would be quite impossible for the journal to allot the necessary space. The Editorial Committee has in several instances been forced to refuse monographs which were well worthy of publication owing to this cause. It has, therefore, been arranged, with the sanction of the Directors, to issue from time to time Monograph Supplements. These will be published in the same form as the journal, and will be issued at a reduced price to subscribers to the journal. We have pleasure in announcing that the first Monograph Supplement, now ready. is the Gifford Edmunds Prize Essay on Interstitial Keratitis, by Mr. W. T. Holmes Spicer. 